\title{
Bariatric surgery metabolic effects in obese individuals associating insulin resistance status
}

\author{
Paula Dejeu', Viorel Dejeu, ${ }^{2,4}$, Danut Dejeu ${ }^{2,4}$, Marius Bembea ${ }^{3,5}$ \\ ${ }^{1}$ Medical Laboratory, Bethany Medical Clinic Oradea, Bihor County, Romania \\ ${ }^{2}$ General Surgery, "Dr. Gavril Curteanu” City Hospital, Oradea, Romania \\ ${ }^{3}$ Pediatrics and Clinical Genetics, "Dr. Gavril Curteanu" City Hospital, Oradea, Romania \\ ${ }^{4}$ General Surgery, MedLife Genesys Hospital, Arad, Romania \\ ${ }^{5}$ Faculty of Medicine and Pharmacy, University of Oradea, Romania
}

\begin{abstract}
Background and aims. Metabolic syndrome or insulin-resistance syndrome is an obesity related condition that increases the risk of developing type 2 diabetes mellitus over time. In this prospective study, overweight and obese individuals were assessed for insulin-resistance status by the HOMA indexes.

Material and methods. 48 bariatric patients associating metabolic syndrome were assessed before and 6 months after the surgery procedure (gastric sleeve, gastric by-pass). The assessment included the following laboratory blood tests: glucose, insulin, HOMA1 index and HOMA2 index before meal.

Results. There was a significant improvement of insulin resistance status in obese patients who underwent bariatric surgery.

Conclusions. Insulin resistance status in obese individuals improves significantly after bariatric treatment.
\end{abstract}

Keywords: insulin resistance, HOMA index, obesity, bariatric surgery

\section{BACKGROUND AND AIMS}

Obesity is a pathological condition characterized by a mixed disorder of metabolic processes of the organism with a change in its energy balance. In some genetic syndromes, obesity is the phenotypical manifestation of a single gene, but in more than $90 \%$ of cases this disease is the result of a multiple pathogenic factors which mainly disrupt the balance between energy intake and energy consumption.

Bariatric surgery is a modern approach in obesity treatment with proven results in rapid and sustained body weight loss. The weight loss itself induces beneficial metabolic effects and improves intestinal hormone secretion [1], but surgical treatment of obesity appears to provide suitabe circumstances for maintaining a long-term downward trend in body weight.

Currently, the body size of an individual is most frequently evaluated by BMI (body mass index or
Quetelet index) [2], the ratio between weight $(\mathrm{kg})$ and square of height $\left(\mathrm{m}^{2}\right)$.

Therefore, considering BMI values, World Health Organization (WHO) classifies obesity in four categories as follows:

- Overweight: BMI $=25-29.9 \mathrm{~kg} / \mathrm{m}^{2}$, with a mildly increased comorbidity risk associated;

- Obesity Class I: BMI $=30-34.9 \mathrm{~kg} / \mathrm{m}^{2}$, with a moderately increased comorbidity risk;

- Obesity Class II: BMI = 35-39.9 kg/m², with an increased comorbidity risk;

- Obesity Class III or morbid obesity: BMI over $40 \mathrm{~kg} / \mathrm{m}^{2}$, associating a very high comorbidity risk [3].

Insulin resistance syndrome or metabolic syndrome

Insulin resistance is a condition of the organism in which a certain amount of insulin concentration induces a suboptimal response in the peripheral tis- 
sues [4]. Insulin resistance manifests primarily in tissues that are insulin-dependent for intracellular glucose transport, namely hepatic, muscular and adipose tissues [5].

The pathophysiological mechanisms involved in insulin resistance syndrome include genetic or primary defects of target cells, anti-insulin antibodies and accelerated insulin catabolism [6]. Mitochondrial dysfunctions also have a significant role in the development of insulin resistance and associated complications [7]. Insulin resistance plays a major role in the pathogenetic development of metabolic syndrome, which may include at least one of the following: hyperinsulinemia, glucose intolerance, type 2 diabetes mellitus, hypertension, elevated levels of serum triglycerides, low HDL-cholesterol, central obesity [8] and pro-coagulant status characterized by elevated PAI-1 levels.

In 2009, the International Diabetes Federation, the International Society of Atherosclerosis, the World Federation of Cardiology and the American Society of Cardiology defined metabolic syndrome by meeting at least three of the following criteria [9]:

- abdominal obesity (abdominal circumference $>80 \mathrm{~cm}$ in women and $>94 \mathrm{~cm}$ in European males);

- serum triglycerides $>150 \mathrm{mg} / \mathrm{dl}$ or patient following a lipid-lowering medication;

- HDL-serum cholesterol $<40 \mathrm{mg} / \mathrm{dl}$ in men, $<$ $50 \mathrm{mg} / \mathrm{dl}$ in women or patient following a treatment for increasing HDL-cholesterol values;

- systolic blood pressure $\geq 130 \mathrm{mmHg}$ and/or diastolic blood pressure $\geq 85 \mathrm{mmHg}$ or patient following blood presure treatment;

- baseline blood glucose levels $>100 \mathrm{mg} / \mathrm{dl}$ or patient previously diagnosed with diabetes mellitus.

Therefore, metabolic syndrome is not a disease in itself, but a combination of metabolic disorders that can identify individuals at high risk for cardiovascular events and/or type 2 diabetes mellitus. The risk of sudden death is estimated to be five times higher in patients with type 2 diabetes mellitus and three times higher in patients with metabolic syndrome. If type 2 diabetes mellitus is not present, metabolic syndrome increases over time the risk of its occurrence up to five times [10].

\section{HOMA index}

Matthews et al. described in 1985 a method which easily evaluates the insulin resistance status of an organism, namely HOMA index (,Homeostasis model assessment") [11]. Under basal conditions, the relationship between glucose and insulin serum levels reflects the balance between liver glucose synthesis and insulin secretion of $\beta$ pancreatic cells maintained through a feed-back loop established between the liver and endocrine pancreas.

HOMA1 index, the initial model, was calibrated to give a normal $100 \%$ pancreatic cell function and a normal insulin resistance of 1 . Increased insulin resistance associates increased basal blood insulin level and suboptimal secretion of pancreatic $\beta$ cells by increasing blood sugar levels. Considering this glucose-insulin interrelation, any pair of basal sugar and insulin blood levels can be used to quantify insulin resistance (IR) and pancreatic $\beta$ cell function $(\% \mathrm{~B})$ using the following formula:

HOMA1-IR $=(\mathrm{IB}(\mu \mathrm{U} / \mathrm{l}) \times \mathrm{GB}(\mathrm{mmol} / \mathrm{l})) / 22.5$, where IB represents basal blood insulin levels before meal, and GB basal blood glucose levels before meal. For basal glucose in $\mathrm{mg} / \mathrm{dL}$, the denominator is 405 .

HOMA index is considered a lab test which has a predictive value in the cardiovascular risk [12]. Furthermore, detection of insulin resistance in non-diabetic subjects using HOMA index test was associated with an increased risk of stroke [13].

Recommendations to determine HOMA index include the following: assessment of patients with BMI over $28 \mathrm{~kg} / \mathrm{m}^{2}$; suspicion of insulin resistance status (metabolic syndrome, type 2 diabetes mellitus); polycystic ovary syndrome [14].

HOMA1 index does not take into account the differences between insulin and hepatic sensitivity, increased insulin secretion and decreased hepatic gluconeogenesis to blood glucose levels above 180 $\mathrm{mg} / \mathrm{dl}$, glycosuria and circulating proinsulin. Therefore, the improved model index HOMA 2 was also calculated in the present study by accessing the website https://www.dtu.ox.ac.uk/homacalculator/ download.php. HOMA2 calculator automatically calculates the insulin resistance after introducing glucose and insulin serum levels, and also reveals the percentage of functional $\beta$-pancreatic cells.

Insulin levels were determined using chemiluminescence detection method (CLIA) and as for glucose, the spectrophotometric method [15].

HOMA index reference values are [16]:

$<2$ - normal;

$>2$ - possible resistance to insulin;

$>2.5$ - increased probability of insulin resistance;

$>5$ - the mean value in type 2 diabetes mellitus.

\section{MATERIAL AND METHOD}

The present prospective clinical trial was conducted from January 2017 to September 2018, at the Laboratory Department of Bethany Medical 
Clinic Oradea over the patients who underwent bariatric surgery at MedLife Genesys Hyperclinic Arad, Bariatric Surgery Department.

\section{Study design and patients}

The laboratory blood tests for the eligible subjects were performed in Oradea at Bethany Private Medical Center. The patients included in the study were overweight and obese individuals associating metabolic syndrome assessed in order to receive a bariatric treatment, namely gastric sleeve or gastric by-pass. The following flowchart (Figure 1) presents the selection algorithm for the eligible patients.

635 patients assessed before the bariatric surgery
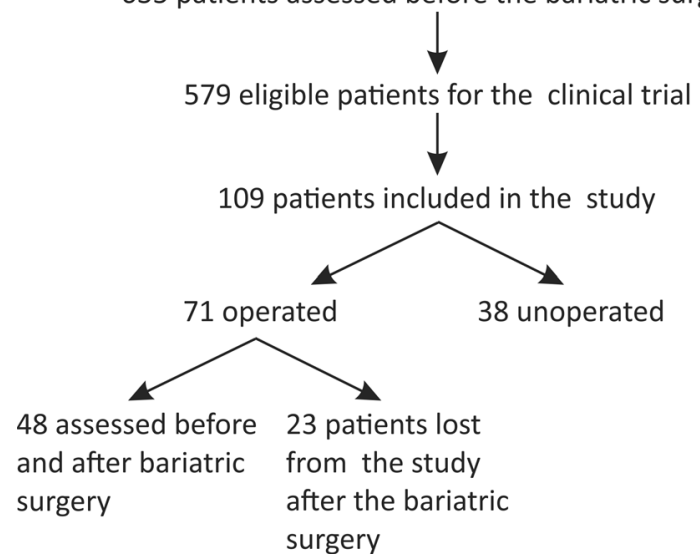

FIGURE 1. The selection algorithm of eligible patients

Laboratory, anthropometric and clinical data collection

Before bariatric surgery and 6 months thereafter, the patients enrolled in the study were assessed for the following laboratory tests: insulin, glucose serum levels and HOMA indexes before meal.

The clinical evaluation included the following: weight, height, body mass index (BMI), abdominal circumference, blood pressure, family history of overweight/obesity and comorbidities.

\section{Statistical analysis}

In terms of followed trend in time, comparison of mean values was performed using the Student pair test for normal distribution variables and the Wilcoxon test for those with asymmetric distribution. The statistical significance limit was 0.05 .

\section{RESULTS}

\section{Distribution by gender}

109 patients were enrolled in the study, of which $83(76.1 \%)$ were female and $26(23.9 \%)$ male: $p<$ 0.0001, Chi-Square test (Figure 2).

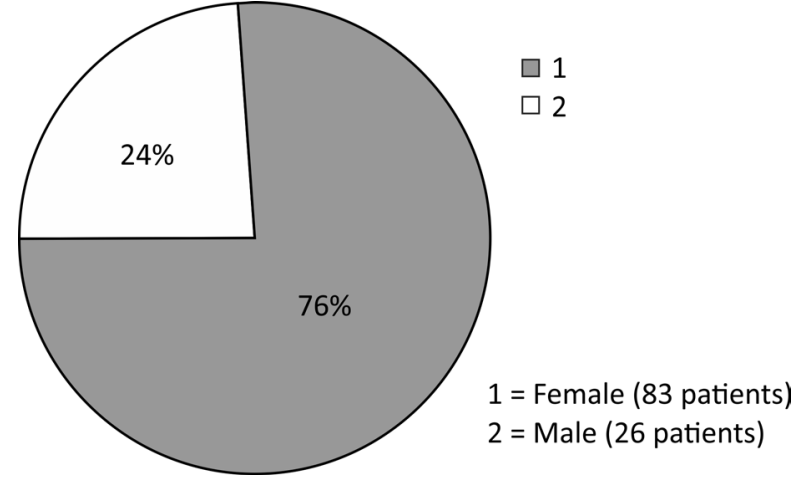

FIGURE 2. Distribution by gender of the enrolled group (percentage\%)

Considering only the patients who came for the $6^{\text {th }}$ month follow-up assessment, the ratio becomes even more unequal: out of 48 patients, 41 (85.4\%) were women and only $7(14.6 \%)$ men $(\mathrm{p}<0.0001$, Chi-Square test).

By comparing these data with the gender distribution in the group that didn't show up at the postoperative assessment, we obtain the following data:

TABLE 1. Gender distribution in the lost group and the enrolled group

\begin{tabular}{|l|c|c|}
\hline Gender & $\begin{array}{c}\text { Lost group } \\
(\mathbf{n}=\mathbf{6 1 )}\end{array}$ & $\begin{array}{c}\text { Enrolled group } \\
(\mathbf{n}=\mathbf{4 8})\end{array}$ \\
\hline Female nr. (\%) & $42(68.9)$ & $41(85.4)$ \\
\hline Male nr. (\%) & $19(31.1)$ & $7(14.6)$ \\
\hline
\end{tabular}

There is a higher ratio in women among controls, but the difference does not reach the statistical significance: $p=0.0738$, Yates correction (Figure 3).

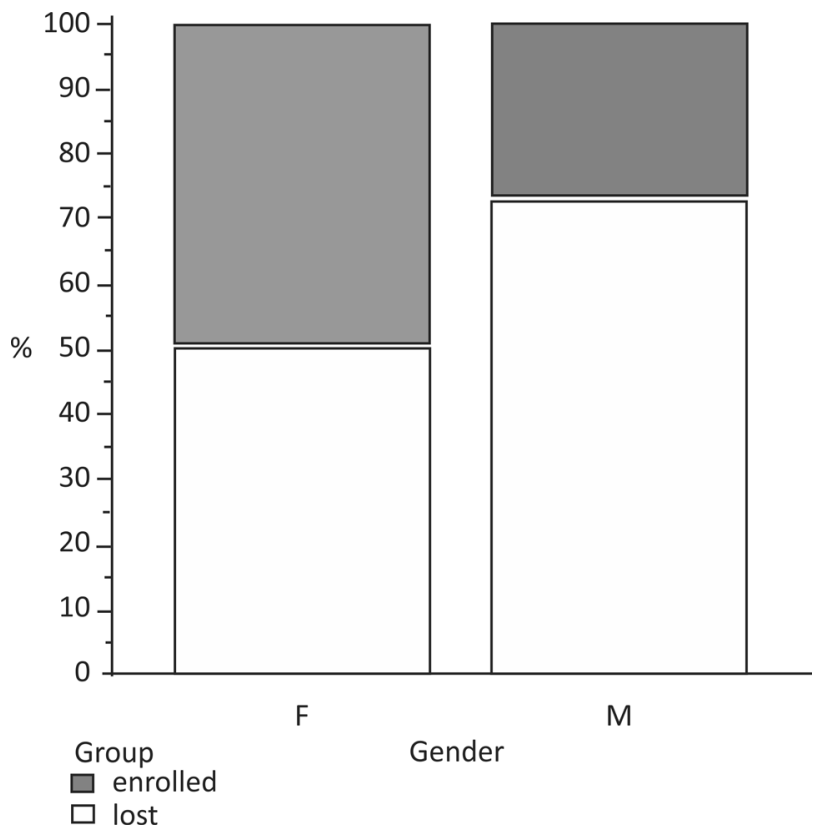

FIGURE 3. Distribution of the lost group and the enrolled group by gender (percentage\%) $M=$ male,$F=$ female 


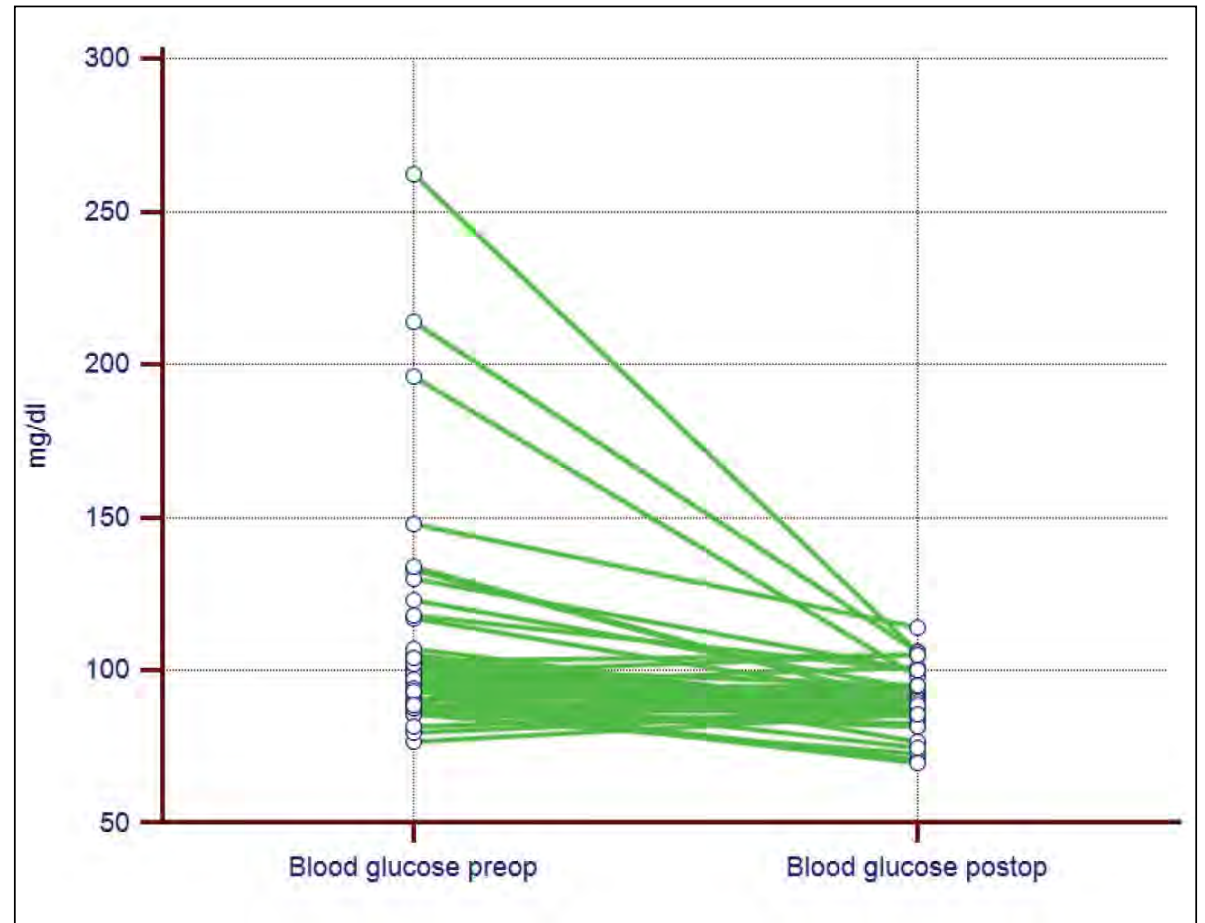

FIGURE 4. Glucose serum levels before bariatric surgery and at 6 months thereafter

\section{Glucose serum levels pre- and postoperative}

Glucose levels before meal registered a decreasing trend of marked significance: the median preoperative value was $98 \mathrm{mg} / \mathrm{dl}$ and postoperatively $89 \mathrm{mg} / \mathrm{dl}$ ( $\mathrm{p}<0.0001$, Wilcoxon test) (Figure 4).

\section{Insulin serum levels pre- and postoperative}

The insulin level also registered a significant decrease: from the mean value of $20.6 \mu \mathrm{U} / \mathrm{ml}( \pm 14.0)$ to mean values of $6.64 \mu \mathrm{U} / \mathrm{ml}( \pm 3.8)(\mathrm{p}<0.0001$, the Student test for dependent batches) (Figure 5).

\section{HOMA 1 and HOMA 2 indexes pre- and} postoperative

The following table reveals the geometrical mean values for HOMA 1 and HOMA 2 risk indexes.

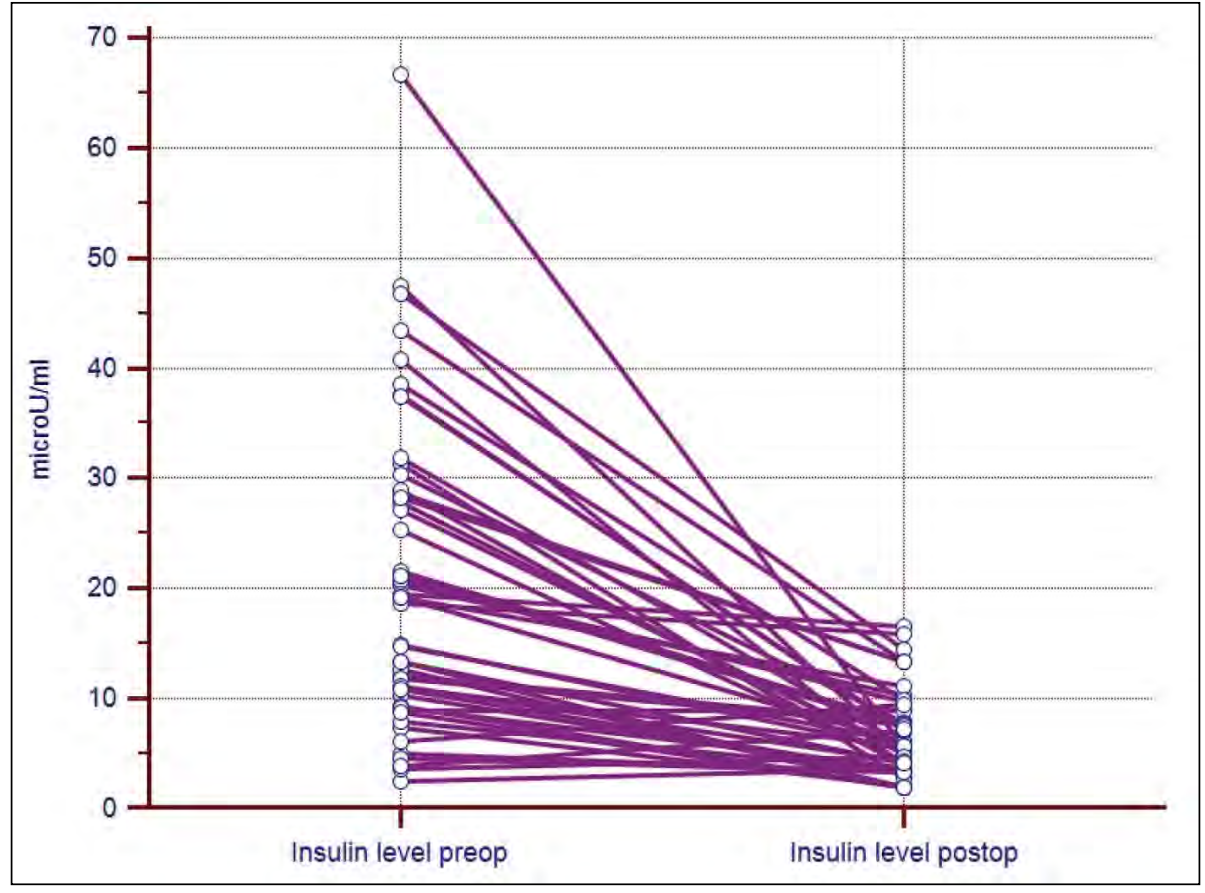

FIGURE 5. Insulin serum levels before bariatric surgery and at 6 months thereafter 
TABLE 2. Geometrical mean values for HOMA 1 and HOMA 2 risk indexes

\begin{tabular}{|l|c|c|c|}
\hline Index & $\begin{array}{c}\text { Preoperative } \\
(\mathbf{n}=\mathbf{4 8})\end{array}$ & $\begin{array}{c}\text { Postoperative } \\
(\mathbf{n}=\mathbf{4 8})\end{array}$ & $\begin{array}{c}\text { Statistic } \\
\text { significance (p) }\end{array}$ \\
\hline $\begin{array}{l}\text { HOMA 1 - } \\
\text { geometrical } \\
\text { mean value }\end{array}$ & $4.3(3.2-5.6)$ & $1.2(1.0-1.5)$ & $<0.0001$ \\
\hline $\begin{array}{l}\text { HOMA 2 - } \\
\text { geometrical } \\
\text { mean value }\end{array}$ & $2.3(1.8-3.0)$ & $\begin{array}{c}0.76(0.65- \\
0.85)\end{array}$ & $<0.0001$ \\
\hline
\end{tabular}

After studying the results shown in this table, the decrease of HOMA indexes after bariatric sur- gery becomes obvious. The Figure 6 and Figure 7 further emphasizes these differences.

\section{Percentage of functional $\beta$ pancreatic cells pre- and postoperative}

As for the percentage of functional $\beta$ pancreatic cells, we noticed a statistically significant decrease: the preoperative arithmetic mean is $144.2( \pm 74.9)$ and the postoperative, $86.0( \pm 34.9)(\mathrm{p}<0.0001$, Student test for dependent batches) (Figure 8).
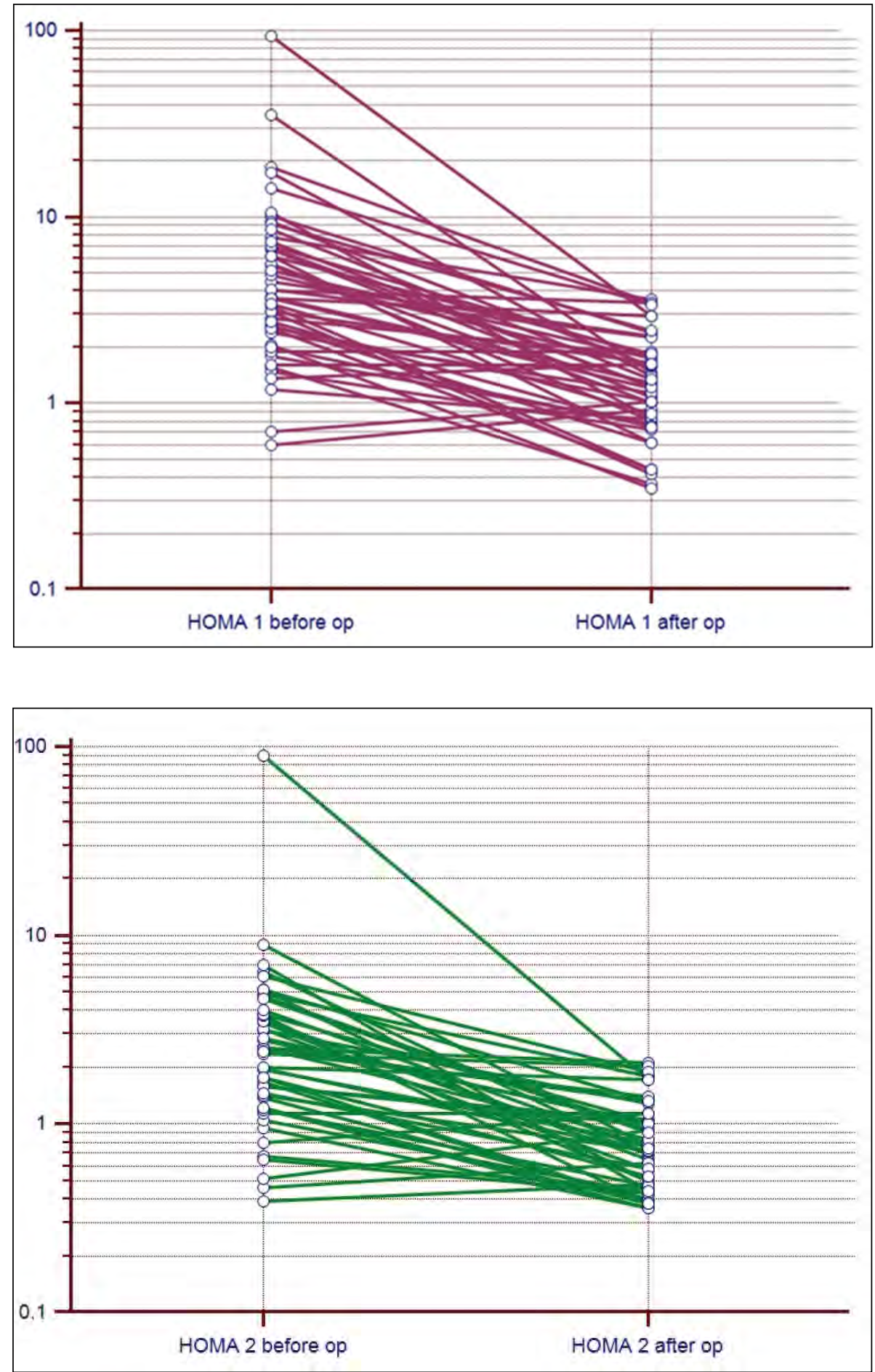

FIGURE 6. HOMA1 index values before and after bariatric surgery 


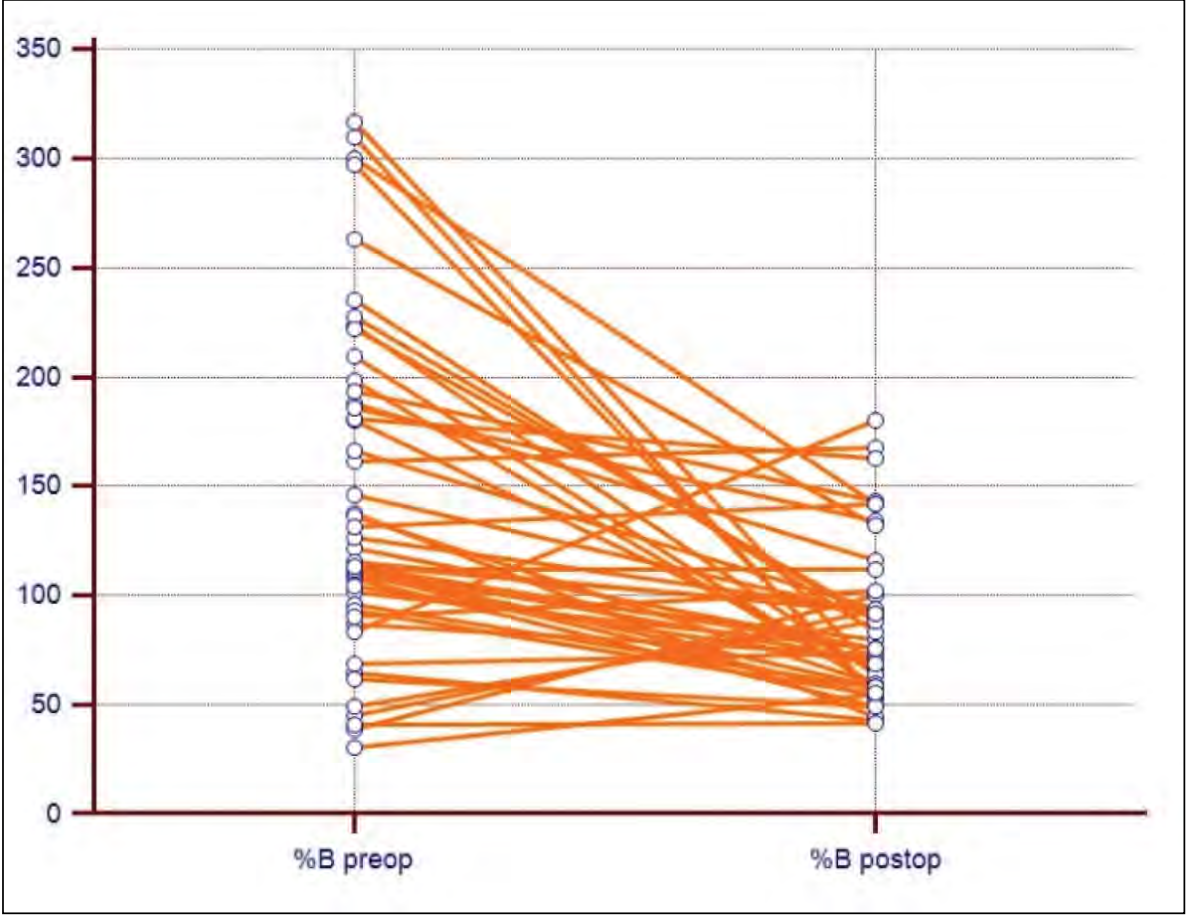

FIGURE 8. Percentage of functional $\beta$ pancreatic cells pre- and postoperative

\section{DISCUSSIONS}

The gender distribution results of this study fall within the limits observed in the literature [17]. Thus, the ratio between genders, clear-cut suitable for the feminine gender, follows the trend observed in similar studies. Both the percentage of preoperative group $(76.1 \%)$ and study group $(85.4 \%)$ remain in the range of these studies indicating a female percentage of 60 to $90 \%$.

The results regarding the levels of serum insulin and blood glucose obtained in this study are consistent with other similar studies $[18,19]$. The incidence of elevated blood glucose levels before meal decreased significantly 6 months after the bariatric procedures (gastric sleeve, gastric by-pass). For the patients with a short history of diabetes, insulin resistance may be the major cause of the disease and not $\beta$ pancreatic cell dysfunction [20,21]. Thus, increasing insulin sensitivity is an effective treatment for type 2 diabetes mellitus. The decrease trend of HOMA1 and HOMA2 indexes along with the opti-

\section{REFERENCES}

1. Lim EL, Hollingsworth KG, Aribisala BS, Chen MJ, Mathers JC, Taylor R. Reversal of type 2 diabetes: Normalisation of beta cell function in association with decreased pancreas and liver triacylglycerol. Diabetologia. 2011 Oct; 54(10):2506-14.

2. Garrow JS, Webster J. Quetelet's index (W/H2) as a measure of fatness. Int. J. Obes. 1985, 9(2):147-153. mized functionality of $\beta$ pancreatic cells indicates an improvement in insulin resistance status with a good long-term prognosis for the individual. Postoperative HOMA1 index is considered an independent predictor factor for the complete remission response of diabetes mellitus [22]. The results of our study regarding the decrease of HOMA1 index fall within the variability observed in the specialty literature.

\section{CONCLUSIONS}

Excess adipose tissue has a baneful effect on carbohydrate and lipid metabolisms. One of the bariatric surgery beneficial effects is a quick significant improvement in the insulin resistance status in obese individuals, registering a decreasing risk of developing type 2 diabetes mellitus over time. Thus, bariatric procedures should be considered first therapeutic option in obese patients associating metabolic syndrome and/or type 2 diabetes mellitus.

3. Organisation WH. Obesity and overweight. Fact Sheet, 2006. No.311.

4. Ascaso JF, Pardo S, Real JT, Lorente RI, Priego A, Carmena R. Diagnosing insulin resistance by simple quantitative methods in subjects with normal glucose metabolism. Diabetes Care. 2003 Dec; 26(12):3320-5.

5. Lichiardopol R. Rezistenţa la insulină: Un sindrom cu implicaţii multiple. British Medical Journal, ian 2003. 
6. Reaven GM. Pathophysiology of insulin resistance in human disease. Physiol Rev. 1995 Jul. 75(3):473-86.

7. Kim JA, Wei Y, Sowers JR. Role of mitochondrial dysfunction in insulin resistance. Circ Res. 2008 Feb 29. 102(4):401-14.

8. Reaven G, Abbasi F, McLaughlin T. Obesity, insulin resistance, and cardiovascular disease. Recent Prog Horm Res. 2004. 59:207-23.

9. Alberti KG, Eckel RH, Grundy SM, Zimmet PZ, Cleeman JI, Donato KA, Fruchart JC, James WP, Loria CM, Smith SC Jr; International Diabetes Federation Task Force on Epidemiology and Prevention; Hational Heart, Lung, and Blood Institute; American Heart Association; World Heart Federation; International Atherosclerosis Society; International Association for the Study of Obesity. Harmonizing the metabolic syndrome: A joint interim statement of the International Diabetes Federation Task Force on Epidemiology and Prevention; National Heart, Lung, and Blood Institute; American Heart Association; World Heart Federation; International Atherosclerosis Society; and International Association for the Study of Obesity. Circulation. 2009 Oct 20;120(16):1640-5.

10. Kassi E, Pervanidou P, Kaltsas G, Chrousos G. Metabolic syndrome: Definition and controversies. BMC Med 2011, 9:48.

11. Matthews DR, Hosker JP, Rudenski AS, Naylor BA, Treacher DF et al. Homeostasis model assessment: insulin resistance and $\beta$-cell function from fasting plasma glucose and insulin concentrations in man. Diabetologia 1985, 28: 412-419.

12. Gast KB, Tjeerdema N, Stijnen T, Smit JW, Dekkers OM. Insulin resistance and risk of incident cardiovascular events in adults without diabetes: Meta-analysis. PLoS One. 2012;7(12):e52036.

13. Katsuki A, Sumido Y, Gabazza E et al. Homeostasis Model Assessment Is a Reliable Indicator of Insulin Resistance During Follow-up of Patients With Type 2 Diabetes. Diabetes Care 2001, 24:362-365.
14. Rundek T, Gardener H, Xu Q, Goldberg RB, Wright CB, Boden-Albala $B$, Disla N, Paik MC, Elkind MS, Sacco RL. Insulin resistance and risk of ischemic stroke among nondiabetic individuals from the northern Manhattan study. Arch Neurol. 2010 Oct;67(10):1195-200.

15. Laborator Betania Oradea. Referinţele specifice tehnologiei de lucru utilizate. 2016. Ref Type: Catalog.

16. Beineke M. Marker for the diagnosis of insulin resistance. Labor Bioscientia. www.bioscientia.de. Ref Type: Internet Communication.

17. Freitas WR Jr, Oliveira LVF, Perez EA et al. Systemic Inflammation in Severe Obese Patients Undergoing Surgery for Obesity and Weight-Related Diseases. Obes Surg 2018; 28(7): 1931-1942.

18. Dardzinska JA, Malgorzewicz S, Kaska L, Proczko M, Stefaniak T, Stankiewicz M, Sledzinski Z: Fasting and postprandial acyl and desacyl ghrelin levels in obese and non-obese subjects. Endokrynologia Polska 2014; 65(5), 377-381.

19. Zhu Y, Sun Z, Du Y, Xu G, Gong K et al. Evaluation of insulin resistance improvement after laparoscopic sleeve gastrectomy or gastric bypass surgery with HOMA-IR. Biosci Trends 2017; 11(6): 675-681.

20. McEvoy CT, Cardwell CR, Woodside JV, Young IS, Hunter SJ, McKinley MC. A posteriori dietary patterns are related to risk of type 2 diabetes: Findings from a systematic review and meta-analysis. J Acad Nutr Diet 2014; 114:1759-1775.

21. Kotani K, Imazato T, Anzai K, Kyushu Diabetes Testing Study G. Expected role of medical technologists in diabetes mellitus education teams. Biosci Trends. 2015; 9:205-206.

22. Schauer PR, Kashyap SR, Wolski K, Brethauer SA, Kirwan JP, Pothier CE et al. Bariatric surgery versus intensive medical therapy in obese patients with diabetes. N Engl J Med 2012; 366(17):1567-76. 